\title{
Permanent coma patient re-learned to speak via coordination dynamics therapy
}

\author{
Giselher Schalow* \\ Institute of Exercise Biology and Physiotherapy, Centre of Behavioural and Health Sciences, University of Tartu, Estonia
}

\section{Summary}

Following an extreme severe brain injury in a car accident, a 22 -year-old male patient lost approximate $50 \%$ of the brain and switched into the permanent coma state. One year after the accident coordination dynamics therapy (CDT) was stated with 20 hours per week. Following 3 years of CDT he started to reach slowly the minimally consciousness state. Following 5 years of CDT, he was fully out-ofcoma. Movement functions re-appeared and he could communicate with the surrounding. Following 5.5 years of CDT he could move better and say the word 'ma' instead of mama. It was hoped that he could re-learn a few words. Through 5.7 years of intensive CDT, he rather suddenly became able to speak again. He could precisely repeat every word in English or Greek (mother tongue). But he was not able to have a conversation. The missing cognitive functions were still so far missing. Because of the speeding up of the repair, when the patient Manolis was fully out-of-coma it seems that more brain repair is possible through further intensive CDT.

\section{Introduction}

It has been reported before about this patient Manolis who could be brought fully out of the permanent coma through 5 years of coordination dynamics therapy (CDT) $[1,2]$. Because of the importance that such a severely injured patient could even re-learn speaking, it is reported here again about his brain repair achieved through a longlasting intensive CDT.

$\mathrm{CDT}$ is an efficient movement-based-learning treatment to repair the human brain and can also be applied to coma patients [1]. CDT consist of exercising on a special CDT device (Figure 3A) to improve the phase and frequency coordination of neural network organization and the training of movements like creeping, crawling, walking, running, jumping and old-learned movements (for example Figure 6), if possible, so that other parts of the CNS can take function over by plasticity. The scientific basis of this new efficient treatment is the human neurophysiology and especially the electrophysiology with the new recording method, "the single-nerve fiber action potential recording method" [3] and the single-motor unit "surface electromyography" (sEMG).

With the single-nerve fiber action potential recording method one can record at the neuron level simultaneously natural impulse from sets of single-nerve fibers leading into the CNS (spinal cord) and leaving it $[4,5]$ (Figure 1) and analyze human neuronal network organization at the single neuron level [6]. An important finding is the phase and frequency coordination among neuron firings [6], which becomes impaired following injury [7] and has to be repaired. This phase and frequency coordination can also be observed non-invasively when performing sEMG from spinal cord injury patients when a muscle is only innervated by a few motoneurons (Figure 2). The organizations of motor programs can be followed up [8] and the coordinated firing of motor units nicely be seen (Figure 2). When exercising coordinated movements, especially on the special CDT device (Figure $3 \mathrm{~A}$ ), there is learning transfer [9] from movements to other movements, to urinary bladder functions [10], to speech induction [1] and to higher mental functions [1].

\section{Method}

The CDT of the coma patient consisted mainly of the exercising on the special CDT device for improving mainly the impaired phase and frequency coordination (Figure 3A-B) and the sky-walking (Figure $3 \mathrm{C}-\mathrm{D})$ to train the walking and the upright position for not getting an orthostasis syndrome. Additional conventional physiotherapy and some speech therapy were administered to him

\section{Results}

The 22-year-old man Manolis suffered in a car accident an extreme severe brain injury. In the accident a metal shard went into his right brain and nervous tissue was lost. The severances of the injury can partly be seen in Figure 4. After surgery in a university clinic, he was send to a conventional rehabilitation center. At the beginning of rehabilitation, the relations could communicate with the patient by eye blinking. After a few months this communication was lost. The pathologic processes seemed to have won against the physiologic ones. The family did not want that Manolis would die, so they took him out of the rehabilitation center and started CDT at home with a lot of vegetative nervous system problems at the beginning as for example the blood pressure.

Realizing the tremendous damage of the brain of Manolis (Figure 4), the Author himself had doubts whether it would be possible to get him out-of-coma through CDT. Based on his experience with rehabilitation, the neurosurgeon who operated the patient after the accident predicted that the family members should be happy if they could keep the health level of Manolis (Figure 5A), which means staying in the permanent coma for ever till he would die in a complication in approximately 5 years.

Following 3 to 5 years of CDT with 20 hours therapy per week, Manolis came via the minimally consciousness state [11] out-of-coma.

${ }^{*}$ Correspondence to: Giselher Schalow, Institute of Exercise Biology and Physiotherapy, Centre of Behavioural and Health Sciences, University of Tartu, 5 Jakobi Street, Tartu 51014, Estonia, E-mail: g_schalow@hotmail.com

Received: August 10, 2018; Accepted: August 20, 2018; Published: August 25, 2018 


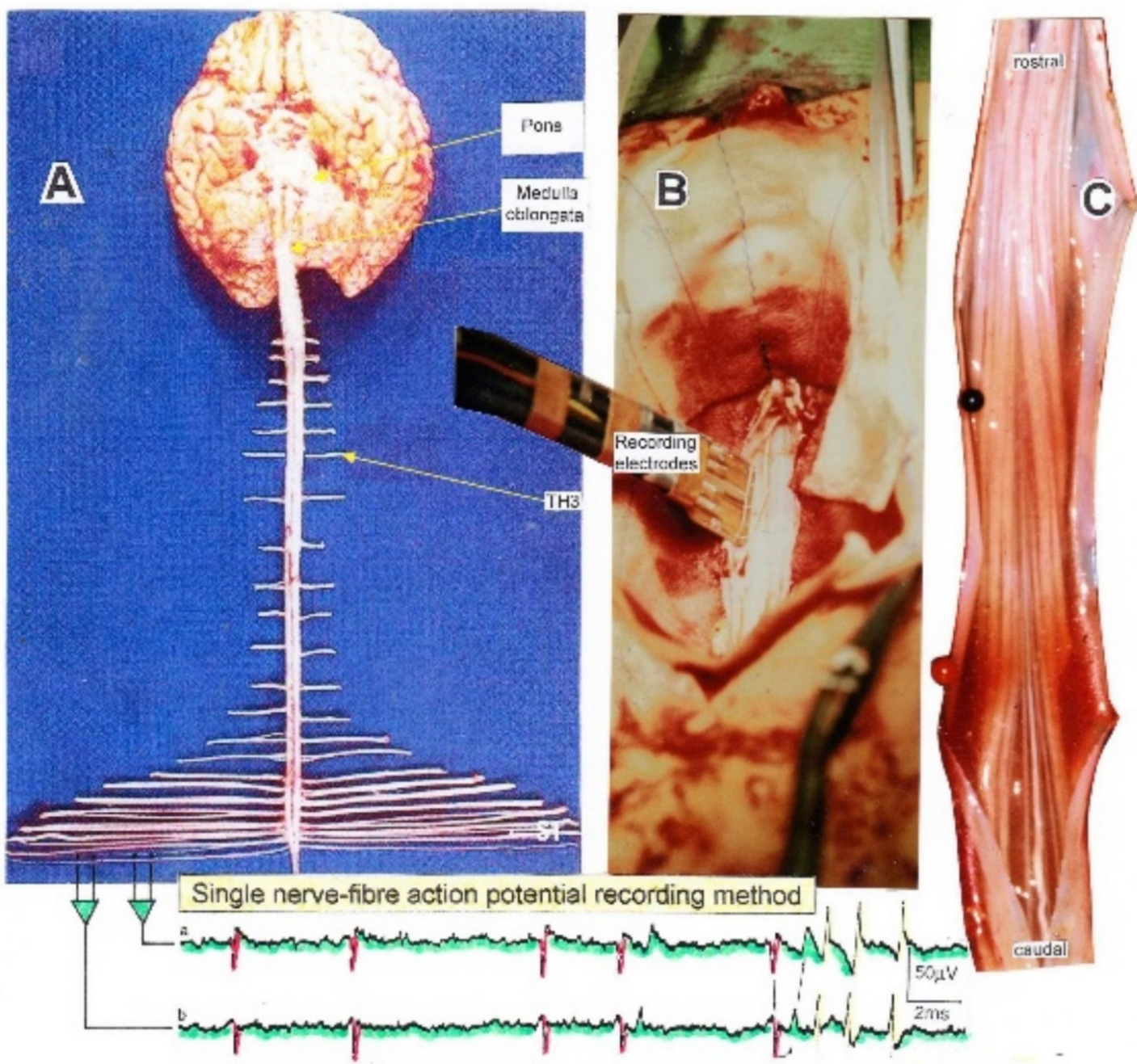

Figure 1. Layout of the recording of single-nerve fiber action potentials to analyze the self-organization of neuronal networks of the human CNS under physiologic and pathophysiologic conditions. By recording with two pairs of platinum wire electrodes (B) from sacral nerve roots (cauda equina, C) containing between 200 and 500 myelinated nerve fibers, records were obtained in which single-nerve fiber action potentials (APs) were identified from motoneuron axons (main AP phase downwards) and afferents (main AP phase upwards). By measuring the conduction times and with the known electrode pair distance $(10 \mathrm{~mm})$, conduction velocity distribution histograms were constructed in which the myelinated nerve fiber groups larger than $4 \mu \mathrm{m}$ could be characterized by group conduction velocity values. After the recording, morphometry was performed. Distributions of nerve fiber diameters were constructed and nerve fiber groups were characterized by the peak values of asymmetrical distributions. By correlating the peak values of the velocity distributions with those of the diameter distributions obtained for the same root, a classification scheme was constructed of the human peripheral nervous system. It became thus possible to record natural impulse patterns simultaneously from identified single afferent and efferent nerve fibers and to analyze self-organizing mechanisms of the human CNS under physiologic and pathologic conditions.

When the Author saw him first time to lift his head and kissed the mother, after 4 years of CDT, he had the feeling that Manolis raised from the dead. After 3 years of CDT, the permanent coma patient slowly reached the minimally consciousness state [11]. After five years of CDT, six years after the accident, Manolis was fully out-of-coma. He could play and laugh with the mother and sit freely on bed. He could generate sounds, but could not speak. The left hemisphere, where the main speech centers are, was not damaged that much. It could therefore be that the patient could also re-learn a bit to speak. After being out of the coma and being able to move a bit on volition the head, trunk and right arm, it seemed that the repair of the former coma patient speeded up. But there were a lot of spasticity and pain problems and whether he could reach the meaningful life state was unclear.

After 5 years of CDT, six years after the accident, the patient could keep the crawling position. He could also sit freely, but he could not stand and walk.
Following 5.5 years of CDT, 6.5 years after the accident, Manolis became able to activate old-learned movement patterns as eating and playing violin (Figure 6). Old-learned movements are helpful for CNS repair, because they are stored in the cerebellum or other lower parts of the CNS. If for example patients could ride a bicycle before the accident, this movement pattern should be used, if possible, also for repair.

Manolis could still not speak. When being pushed to say mama, he succeeded to say 'ma'. May be he could re-learn with further therapy to say 'yes' and 'no' and 'mama' and 'papa', especially because it seemed that the brain repair speeded up. But his repairing brain through CDT found another way to speech.

Through 5.7 years of CDT, 6.7 years after the accident, Manolis became nearly suddenly able to speak again, which was completely unexpected. He could repeat every word in Greek (mother tongue) or English. The pronunciation was good. The mother said, that when her son became able to speak at the 20.7.2018, she had the feeling to have 


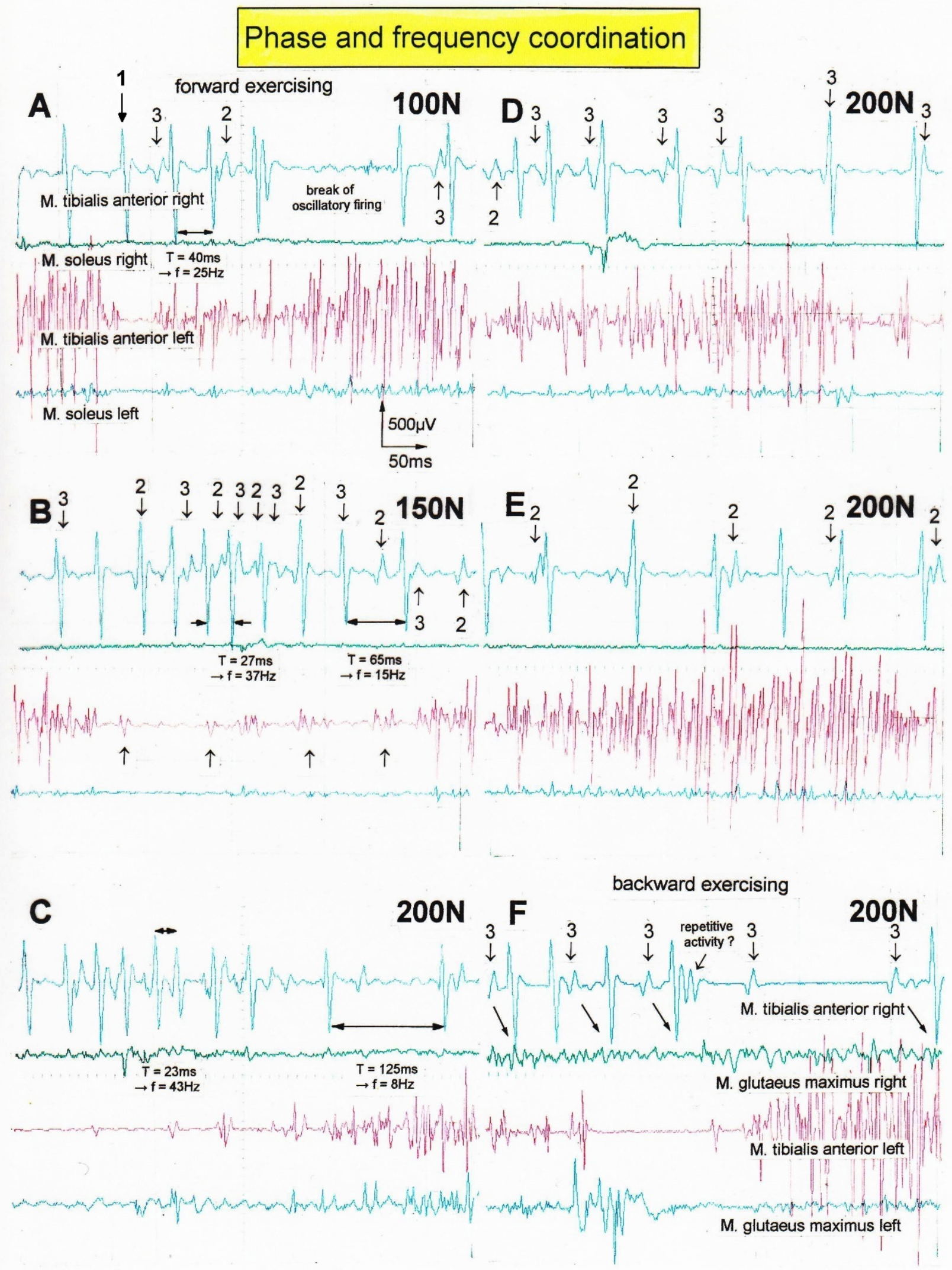

Figure 2. Recording phase and frequency coordination between oscillatory firing motor units $(1,2,3$; FF-type) by sEMG during the generation of a motor program when exercising on the special coordination dynamics therapy device at loads increasing from 100 to $200 \mathrm{~N}$. Oscillation periods (T) and oscillation frequencies (f [Hz]) of oscillatory firing motor unit 1 are partly indicated. In ' $F$ ', some coordination's between motor unit ' 3 ' and ' 1 ' are marked 

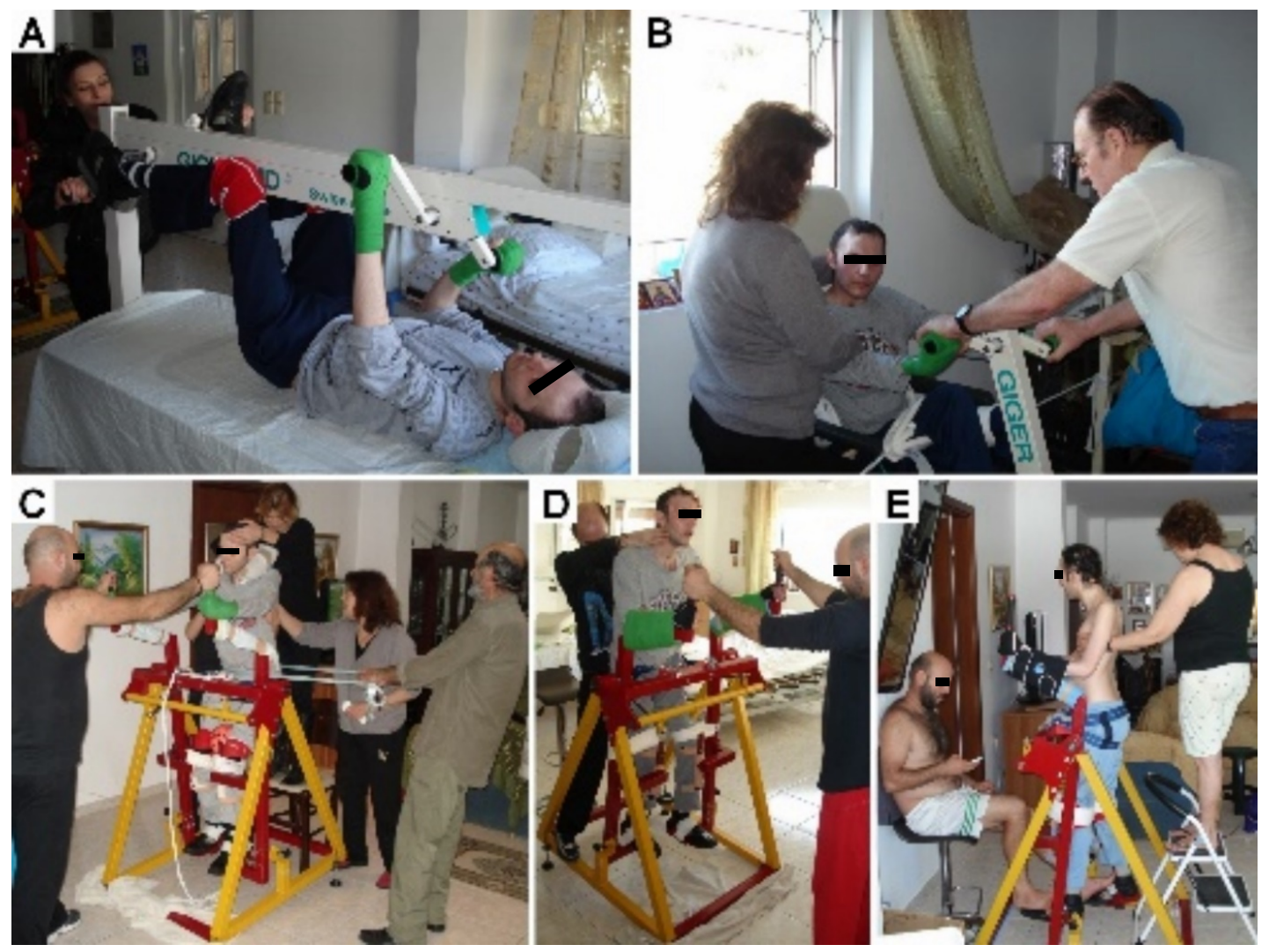

Figure 3. Movements performed with a 23-year-old male patient in the vigilant coma by the family members. All movements were passively performed, because the patient was in coma. A,B. Exercising on the special CDT device in the lying position (both hands are fixed) and sitting position. C,D,E. Exercising on the sky-walker.

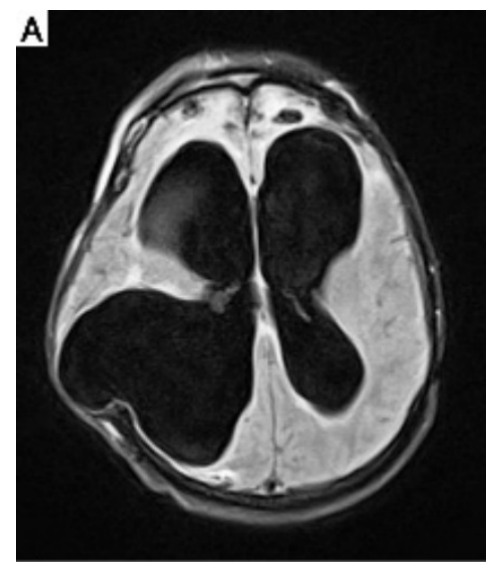

B
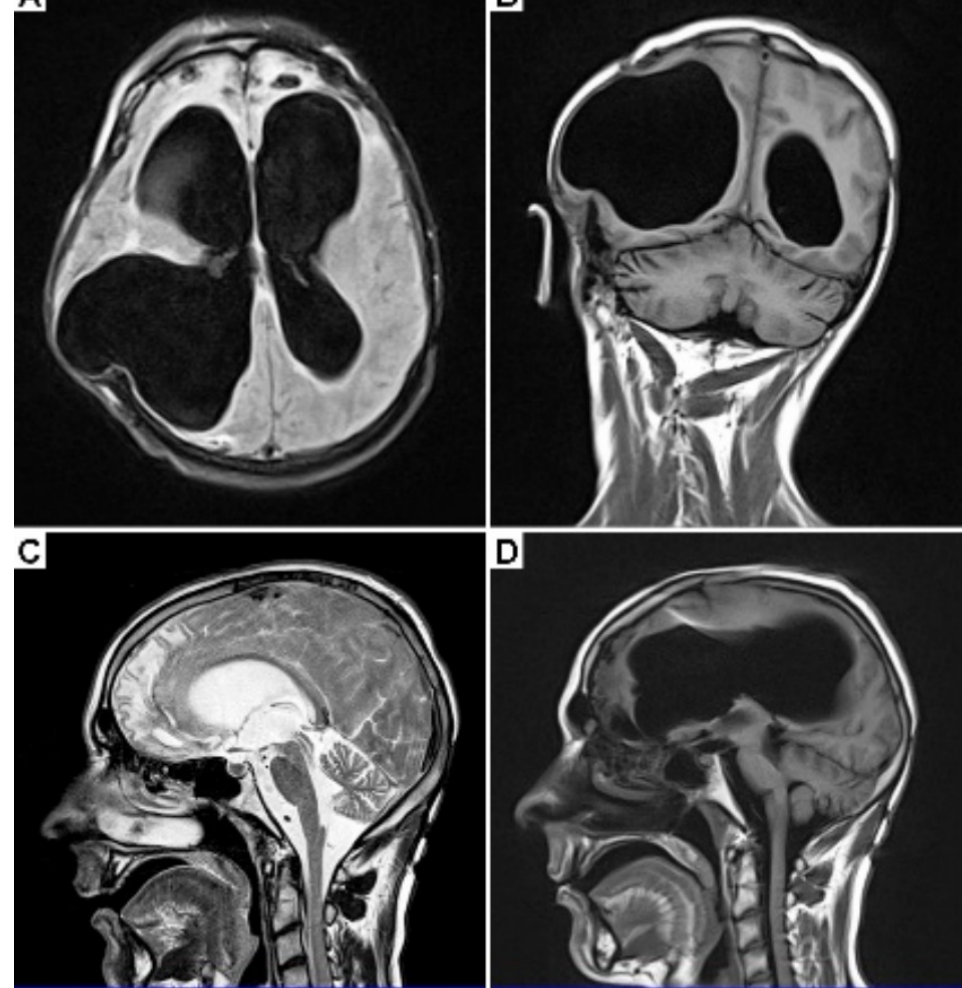

Figure 4. MRI of a 23-year-old male patient with a very severe traumatic brain injury. The pictures were taken one year after the car accident. Since a metal shard went into the brain during the accident, some brain tissue had to be removed. A shunt was installed to regulate brain pressure. Because of the loss of nervous tissue, the ventricles became enlarged; they look like in cases of hydrocephalus. Many parts of the brain were damaged during the accident, including both frontal lobes (A, C). The artifact from the shunt can be seen in ' $\mathrm{C}$ '. 


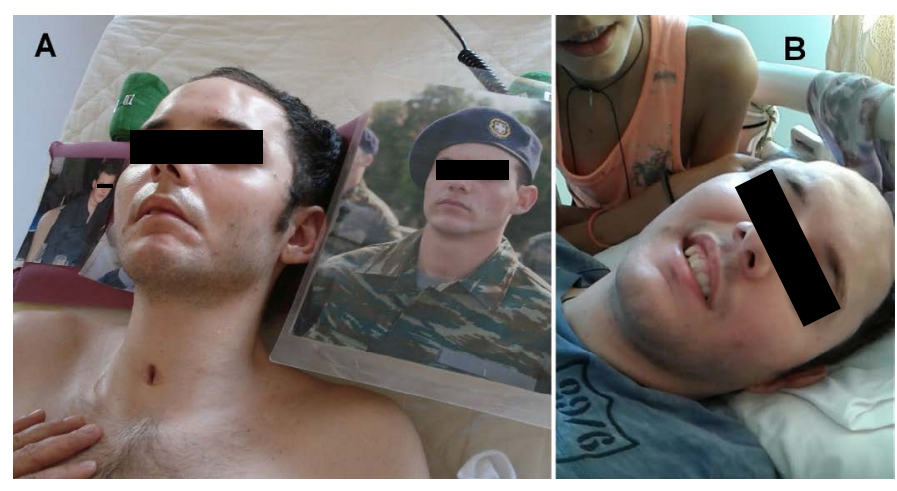

Figure 5. A. Picture of the 23-year-old patient being 1.5 years in the vigilant coma following a car accident. The impression in the face does not look as healthy as the one in the picture made 2 years before when he was in the army. B. The facial expression of Manolis following 5.7 years of CDT during counting in English the numbers one-twothree-four-five. Note the improvement of the expression of his face.

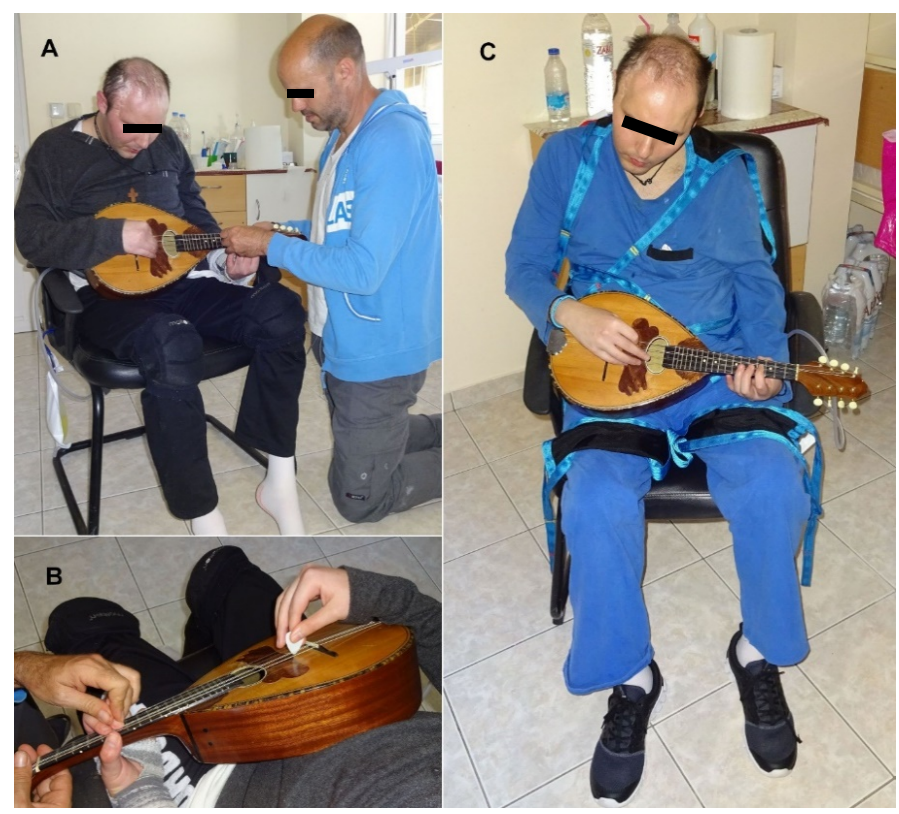

Figure 6. Preparations of the brother (A) to bring Manolis into a proper violin playing position. Note in B, how nicely Manolis can use the right fingers to generate the sound (frequency of up and down finger movements around $5 \mathrm{~Hz}$ ). When playing violin $(\mathrm{C}$ ), his face looks quite healthy. The fingers of the left hand cannot change the sound position because of the lost right hemisphere.

got wings for going on with the treatment. When counting with a girl English numbers, his facial expression looked quite nice (Figure 5B) in comparison to the facial expression after the accident (Figure 5A). Manolis liked it to be helped by children and had less spasticity then.

When playing with one of the sisters, he could also smile (Figure 7).

What a repair was achieved via CDT, if one realizes that Manolis would have died long ago or would have stayed at best in the coma forever.

\section{Discussion}

It was shown that, based on a new development in human neurophysiology, the human nervous system could partly be repaired by a new treatment, called coordination dynamics therapy (CDT) in a patient with an extremely injured brain. Even the speech could be re-established. Manolis could precisely repeat every word in English or Greek and he liked it. During instructive training, when exercising on a special CDT device (Figure 3A) he was even counting 1-2-3, in similarity to a self-instructive training. But a conservation with another person was not possible for him till now because of missing cognitive functions. He could only complain, may be, about pain when he was getting an injection. It is likely that his brain functions can be further improved with intensive CDT. But whether his cognitive functions can substantially be improved and whether he can reach the meaningful life state is unclear.

Actually, two important steps were achieved in this formerly permanent coma patient. The first step was to get him fully out-ofcoma and the second to make him speak again. A third step would be to improve substantially his higher mental functions and connect them to the speech. The big therapy effort was to get him fully out of the permanent coma through approximately 5 -years CDT. The speech was achieved with less effort, namely with approximately 1 -year CDT.

The rather sudden occurrence of the speech makes it likely that the speech areas were in principle operational. But they had to be connected functionally to the whole brain organization again (reconnection treatment). The improvement of the phase and frequency coordination, in the deepness of the complexity of neural network organization (in the association fields), may have contributed to the activation of the speech pattern in some similarity to the activation of the old-learned pattern 'playing violin' (Figure 6).

It has been shown that $\mathrm{CDT}$ can also improve or repair central nervous system (CNS) functioning after stroke [12], traumatic brain injury [13,14], spinal cord injury $[15,16]$, cerebellar injury [17], cerebral palsy [18], hypoxic brain injury [19], in Parkinson's disease [20], spina bifida (myelomeningocele) [21] and scoliosis [22]. Speech had been induced and improved in a patient with severe cerebral palsy [1] and urinary bladder functions were repaired in patients with spinal cord injury $[23,24]$. In patients with cancer, especially breast cancer, cancer growth inhibition could be achieved via CDT [25]. The cardiovascular performance was repaired in the patient Manolis during the first years of CDT [26]. It seems therefore that CDT can improve CNS functioning in every case, even in the extreme case, and since the nervous system is involved in nearly all body functions, CDT can improve human health in general.

Such tremendous repair achieved via CDT, especially in the permanent coma case, seems only possible if the epigenetic regulation

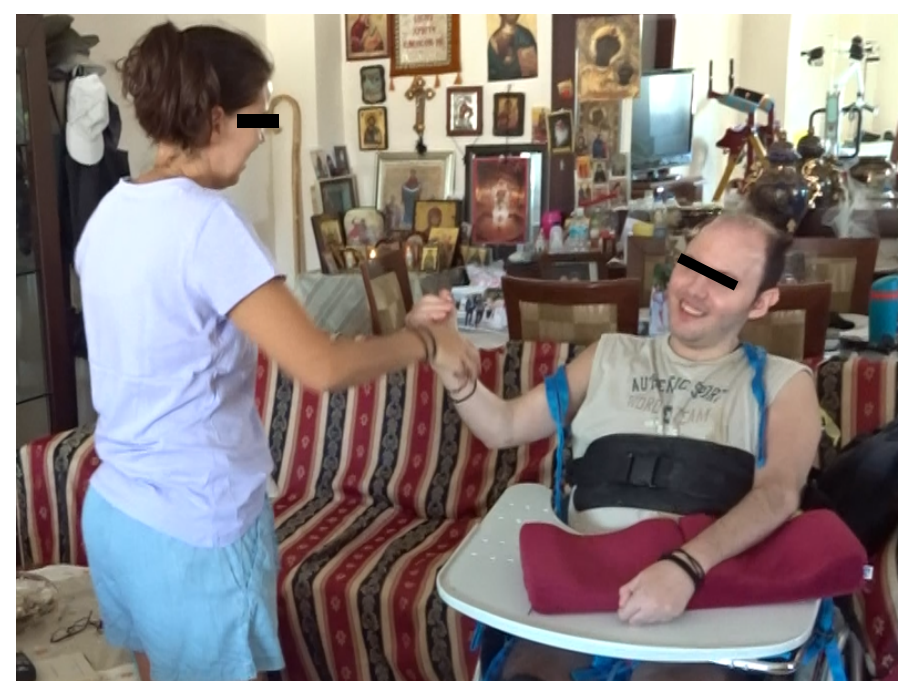

Figure 7. Manolis during playing with a sister. As can be seen from the expression of his face, he enjoyed it. He could smile again. 
for repair had been substantially activated by movement-based learning. CDT had induced the stimulation of those pathways that regulate neural network repair. Epigenetic mechanisms, stimulated by physiologic network activation, are likely key players within signaling networks, as DNA methylation, chromatin remodeling and small non-coding RNAs superfamily and are required for the fine-tuning and coordination of gene expression during neural network repair by learning. The complexity of the epigenetic regulation is tremendous. Figure 8 shows steps of epigenetic regulation induced by specific and coordinated physical activity, namely movement-based learning.

To generate repair in the nervous system, it is likely that permanent changes in gene expression patterns are achieved through permanent changes in chromatin remodeling without changes in DNA sequence. The concept of chromatin remodeling addresses a key challenge of how stable changes in gene expression are induced [27] in neural networks to produce long-lasting changes in repair. DNA methylation is one of the many epigenetic modifications that can alter gene expression.
Dynamic and reversible DNA methylation may be essential for learning and memory formation and could transmit repair influences onto adult neurogenesis.

Understanding the complex epigenetic regulation of neural activity and adult neurogenesis is integral to designing therapeutic approaches to restore neurogenesis and cognitive functions. It will also give a tremendous insight into understanding how certain environmental or pathological influences, such as stress, physical activity, depression and epilepsy regulate adult neurogenesis [28]. Excitation-neurogenesis coupling in adult neural stem/progenitor cells [29] can be achieved through depolarization of membranes generated by physiologic movements.

There are many more patients in the permanent coma who could be brought back to life through CDT. But the first step to get them outof-coma seems to be the biggest one with also the biggest mental load on the therapists.

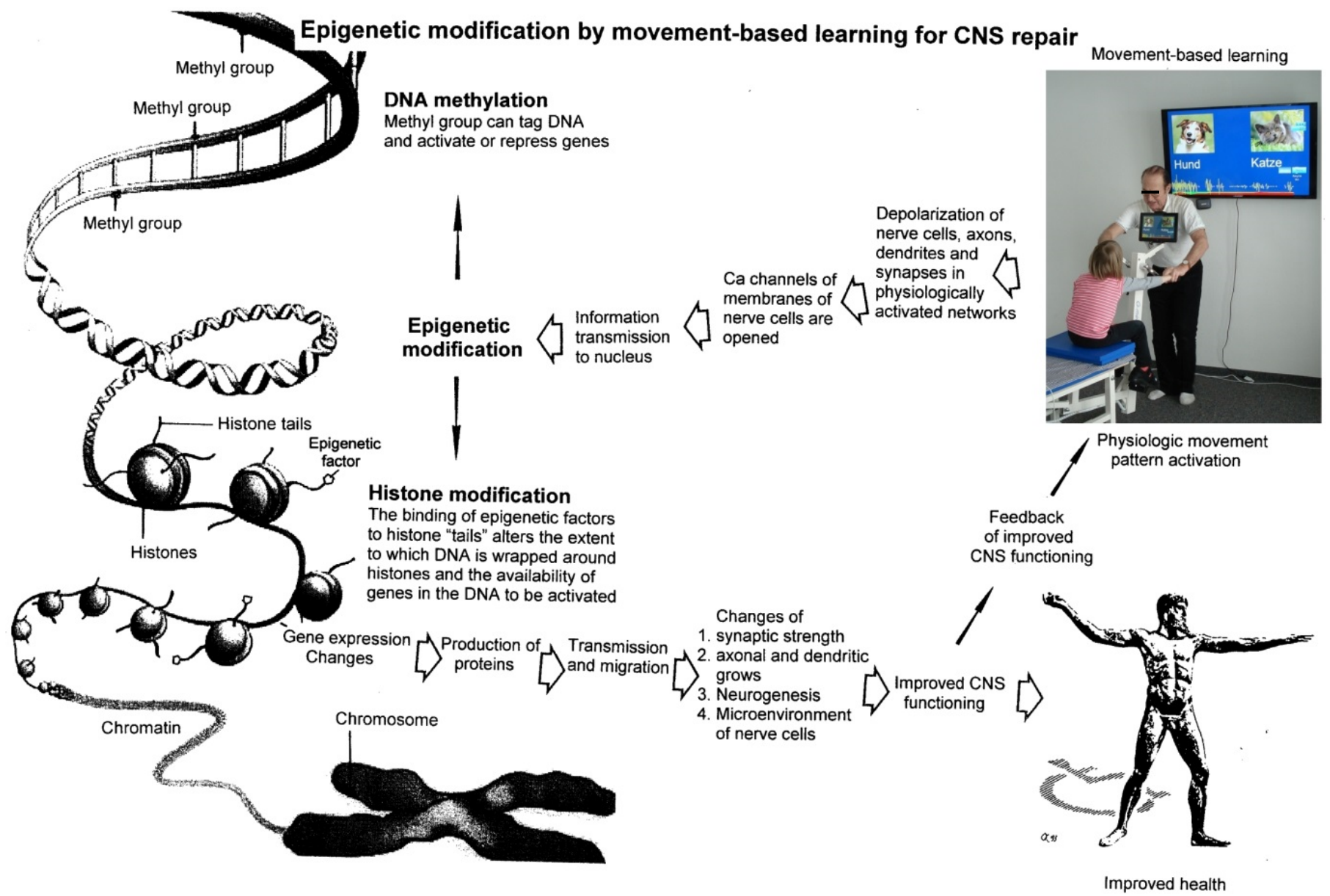

Figure 8. Epigenetic regulation for repair by movement-based learning. CDT-induced stimulation of the pathways that regulate neural network repair is a proven therapeutic and preventive tool. Epigenetic mechanisms, stimulated by physiologic network activation, are likely key players within signaling networks, as DNA methylation, chromatin remodeling and small noncoding RNAs superfamily are required for the fine-tuning and coordination of gene expression during neural network repair by learning. Since the nervous system is involved in nearly all body functions, CDT will improve health. 


\section{Acknowledgement}

The Author is a private researcher in human neurophysiology and clinical research to repair the human CNS and is living and performing research on 1200 Euro. For the upper research project, it was impossible to get funding (including Christopher Reeve Foundation, Swiss National Fond and Deutsche Forschungsgemeinschaft) in the last 30 years, even though the Author studied electronics, theoretical physics and medicine and was post doc with Sir Bernard Katz, Huxley and Ricardo Miledi, Department of Biophysics, University College London. Obviously, to save life of patients or improve their health is not of interest for the world society if a new qualified treatment has to be used.

\section{References}

1. Schalow G (2015) Repair of the Human Brain and Spinal Cord. Nova Science Publisher, Hauppauge NY, USA

2. Schalow G (2018) Coma and spinal cord recovery achieved via coordination dynamics therapy. Clin Case Rep Rev 4: 1-7.

3. Schalow G, Lang G (1987) Recording of single unit potentials in human spinal nerve roots: a new diagnostic tool. Acta Neurochir (Wien) 86: 25-29. [Crossref]

4. Schalow G (1989) Efferent and afferent fibres in human sacral ventral nerve roots: basic research and clinical implications. Electromyogr Clin Neurophysiol 29: 33-53. [Crossref]

5. Schalow G, Lang G (1989) Electrodiagnosis of human dorsal sacral nerve roots by recording afferent and efferent extracellular action potentials. Neurosurg Rev 12: 223232. [Crossref]

6. Schalow G (2005) Phase and frequency coordination between neuron firing as an integrative mechanism of human CNS self-organization. Electromyogr Clin Neurophysiol 45: 369-383. [Crossref]

7. Schalow G (2009) Impaired coordination between oscillatory firing FF and FR-type motor units in Parkinson's disease and patients with spinal cord injury. In: Berkovsky TC (Ed.), Handbook of Spinal Cord Injuries, Chapter 15. 501-517, Nova Science Publishers.

8. Schalow G (2009) Relative Coordination between Neuron firing and Generation of a Motor Program in the human CNS. In: Berkovsky TC (Ed.), Handbook of Spinal Cord Injuries, Chapter 5. 265-295, Nova Science Publishers.

9. Schalow G (2010) Scientific basis for learning transfer from movements to urinary bladder functions for bladder repair in patients with spinal cord injury. Electromyogr Clin Neurophysiol 50: 339-395. [Crossref]

10. Schalow G (2010) Cure of urinary bladder functions in severe (95\%) motoric complete cervical spinal cord injury in human. Electromyogr Clin Neurophysiol 50: 155-179. [Crossref]

11. Schnakers C, et al. (2009) Diagnostic accuracy of the vegetative and minimally conscious state: clinical consensus versus standardized neurobehavioral assessment. BMC Neurol 9: 35.
12. Schalow G (2002) Stroke recovery induced by coordination dynamic therapy and quantified by the coordination dynamic recording method. Electromyogr Clin Neurophysiol 42: 85-104. [Crossref]

13. Schalow G (2002) Improvement after traumatic brain injury achieved by coordination dynamic therapy. Electromyogr Clin Neurophysiol 42: 195-203. [Crossref]

14. Schalow G, Jaigma P (2006) Improvement in severe traumatic brain injury induced by coordination dynamics therapy in comparison to physiologic CNS development. Electromyogr Clin Neurophysiol 46: 195-209. [Crossref]

15. Schalow G, Jaigma P, Belle VK (2009) Near-total functional recovery achieved in partial spinal cord injury ( $50 \%$ injury) after 3 years of coordination dynamics therapy. Electromyogr Clin Neurophysiol 49: 67-91. [Crossref]

16. Schalow G (2003) Partial cure of spinal cord injury achieved by 6 to 13 months of coordination dynamic therapy. Electromyogr Clin Neurophysiol 43: 281-292. [Crossref]

17. Schalow G (2006) Improvement after cerebellar injury achieved by coordination dynamics therapy. Electromyogr Clin Neurophysiol 46: 433-439. [Crossref]

18. Schalow G, Jaigma P (2005) Cerebral palsy improvement achieved by coordination dynamics therapy. Electromyogr Clin Neurophysiol 45: 433-445. [Crossref]

19. Schalow G (2006) Hypoxic brain injury improvement induced by coordination dynamics therapy in comparison to CNS development. Electromyogr Clin Neurophysiol 46: 171-183. [Crossref]

20. Schalow G, Pääsuke, M, Ereline J, Gapeyeva, H (2004) Improvement in Parkinson's disease patients achieved by coordination dynamics therapy. Electromyogr Clin Neurophysiol 44: 67-73. [Crossref]

21. Schalow G, Nyffeler T (2001) Koordinationsdynamik-Therapie: Myelomeningozele (Spina bifida). Physiotherapie.

22. Schalow G, Nyffeler T (2000) Koordinationsdynamik-Therapie: Skoliose Physiotherapie.

23. Schalow G (2010) Cure of urinary bladder functions in severe (95\%) motoric complete cervical spinal cord injury in human. Electromyogr Clin Neurophysiol 50: 155-179. [Crossref]

24. Schalow G (2013) Human Neurophysiology: Development and Repair of the Human Central Nervous System. Nova Science Publisher, New York.

25. Schalow G (2017) Breast cancer grows inhibition via coordination dynamics therapy In: "Horizons in Cancer Research", Volume 68. Nova Science Publisher, New York.

26. Schalow G (2017) Coma recovery achieved after 4 years of coordination dynamics therapy of a patient who lost $50 \%$ of his brain tissue in a car accident. In: "Horizons in Neuroscience Research". Volume 32. Nova Science Publisher, New York.

27. Colvis CM, Pollock JD, Goodman RH, Impey S, Dunn J, et al. (2005) Epigenetic mechanisms and gene networks in the nervous system. J Neurosci 25: 10379-10389. [Crossref]

28. Covic M, Karaca E, Lie DC (2010) Epigenetic regulation of neurogenesis in the adult hippocampus. Heredity (Edinb) 105: 122-134. [Crossref]

29. Deisseroth K, Singla S, Toda H et al (2004) Excitation-neurogenesis coupling in adult neural stem/progenitor cells. Neuron 42: 535-552. [Crossref]

Copyright: (C2018 Schalow G. This is an open-access article distributed under the terms of the Creative Commons Attribution License, which permits unrestricted use, distribution, and reproduction in any medium, provided the original author and source are credited. 